\title{
Collaboration Promotes Proportional Reasoning about Resource Distribution in Young Children
}

\author{
Rowena Ng, Gail D. Heyman, and David Barner \\ University of California, San Diego
}

\begin{abstract}
We investigated how children and adults evaluate the "niceness" of individuals who engage in resource distribution, with a focus on their sensitivity to the proportion of resources given. Across three experiments, subjects evaluated the niceness of a child who gave a quantity of pennies to another child. In Study $1(N=30)$, adults showed sensitivity to the proportion given whereas 5and 7-year-old children did not. In Study $2(N=74)$, both younger (3- to 5-year-old) and older (6to 8-year-old) children were sensitive to proportion only when resources were earned by a giver in collaboration with the recipient rather than by the giver alone. Adults, however, were sensitive to proportion in both cases. In Study $3(N=44)$, we tested 5- and 6-year-olds and their parents to be sure that socio-economic and ethnic differences between samples did not drive results and replicated key findings from Studies 1 and 2. Together, these findings indicate that children favor proportional resource distribution in situations that invoke intuitions about equity. We suggest that these intuitions may form the basis for adult notions of fairness and generosity.
\end{abstract}

\section{Keywords}

Childhood Development; Collaboration; Resource Allocation; Equity (social); Prosocial Behavior; Social Cognition

Is it human nature to share altruistically and to expect others to do so? Or do we begin life expecting resources to flow exclusively from individual efforts and merit? Although humans differ substantially in their attitudes about sharing and resource distribution, the idea that we should share with others according to our means permeates discourse in the western world, from political policy making to religious scripture. Does this sensitivity to sharing and proportional giving come naturally to humans, or does the expectation that people give according to their means result primarily from culturally-mediated learning experiences?

By some accounts, children initially seek to maximize personal gain and selfishly allocate resources to themselves, even when others have contributed to earning the resources in question (Hook, 1978; Lane \& Coon, 1972). According to these studies, children's intuitions about fair resource distribution change gradually as they internalize cultural norms and as they become sensitive to proportionality and the numerical differences between amounts. Children first learn to distribute resources evenly, then to give more to those who work

Address correspondence to Gail D., Heyman, Department of Psychology, University of California, San Diego, 9500 Gilman Dr., La, Jolla, CA 92093-0109; gheyman@ucsd.edu.

Publisher's Disclaimer: The following manuscript is the final accepted manuscript. It has not been subjected to the final copyediting, fact-checking, and proofreading required for formal publication. It is not the definitive, publisher-authenticated version. The American Psychological Association and its Council of Editors disclaim any responsibility or liabilities for errors or omissions of this manuscript version, any version derived from this manuscript by NIH, or other third parties. The published version is available at www.apa.org/pubs/journals/dev 
hardest, and finally, as their numerical sense evolves, to divide resources proportionally, according to the efforts of individuals (Damon, 1975; Damon, 1977; Hook, 1978; Hook \& Cook, 1979; Inhelder \& Piaget, 1964).

In early studies, a barrier to testing the development of equity and fairness intuitions was the finding that children have difficulty reasoning about proportions before the age of 7 (Noelting, 1980; Piaget \& Inhelder, 1958; Piaget \& Inhelder, 1975; Siegler \& Vago, 1978). However, recent studies using simpler methods and stimuli that are more interesting to children have challenged this conclusion (Goswami, 1995; Mix, Levine \& Huttenlocher, 1999; Singer-Freeman \& Goswami, 2001). For example, Singer-Freeman and Goswami (2001) found that children as young as 3 years of age can match the proportions of pizza and candies that have been eaten. Further, research in pre-linguistic infants finds that 6-montholds are sensitive to proportion in simple numerical discrimination tasks (McCrink \& Wynn, 2007). However, there are also well-documented ways in which young children, and sometimes adults, experience difficulty reasoning about proportion (e.g., overlooking the importance of the denominator when reasoning about fractions; Reyna \& Brainerd, 1994; 2008).

In one recent study, McCrink, Bloom, and Santos (2009) found some sensitivity to proportion in 5-year-olds' intuitions about resource distribution. Children played a "Giving Game" in which they received tokens from two animal puppets and were asked to judge which puppet was nicer. Across trials, the total number of tokens that each animal possessed was manipulated, as was the number that each animal gave to the child. In one key set of contrasts, the experimenters pitted the absolute amount against the proportion (i.e., one puppet shared 3 of his 4 chips, and the other puppet shared 6 of his 12 chips). In this way, the experimenters tested children's sensitivity to proportion when assessing generosity. Whereas adults based their niceness judgments on the proportion given on these trials, 4and 5-year-olds systematically judged that the puppet who gave a larger absolute amount was nicer. When the two puppets gave identical amounts, 5-year-olds, but not 4-year-olds, now exhibited some sensitivity to proportion. Overall, however, children were far less sensitive to proportion than were adults, and instead favored individuals who gave a greater absolute amount.

The results of McCrink et al. (2009) raise the question of why children and adults differ in their evaluations of niceness. One possibility is that young children are unable to reason about proportion in this type of experimental setting - e.g., because of the need to simultaneously represent two quantities and compare them. Although this is possible, it is unlikely since the study was similar to other recent experiments that have found greater sensitivity to proportion, like those mentioned above. Another possibility is that children and adults have distinct meanings for the word nice, and it is for this reason that only adults consider fairness when interpreting it. However, previous studies suggest that in some contexts, children and adults treat nice similarly (e.g., Heyman \& Gelman, 1998, 1999). For example, Heyman and Gelman (1999) showed that, like adults, children as young as age 4 think that the words nice and mean relate to mental life, rather than simply reflecting types of behaviors. Finally, a third possible explanation for McCrink et al.'s finding of age-related differences, which we explore in the present research, is that children initially reserve the use of proportion information to situations that invoke intuitions of merit, where resources are distributed according to each individual's contribution to acquiring them (e.g., where $50 \%$ of effort merits $50 \%$ of the resources, rather than $20 \%$ ). On this proposal, early proportional reasoning may depend on children having specific expectations about how all resources should be distributed. When two individuals give generously - i.e., without an obligation to give - children may not attend to leftover resources because they do not have expectations that they should be shared. Adults, in contrast, may recognize that 
differentiating the "niceness" of two generous acts can only be done relative to the giving power of each individual, and thus may actively consider leftover resources when making their judgments. Adults, but not children, may expect individuals to share according to their means.

We assessed this possibility by comparing reasoning in a non-collaborative context like that used by McCrink et al. (2009) to a collaborative context in which recipients contributed to the acquisition of the resources they were given. Previous studies find that, for adults, collaborative contexts make the notion of equitable resource distribution highly salient (Cappelen, Hole, Sorensen, \& Tungodden, 2007; Cherry, Frykblom, \& Shogren, 2002; Frohlich, Oppenheimer, \& Kurki, 2004; Oxoby \& Spraggon, 2008; Ruffle, 1998). Also, there is recent evidence that preschoolers distribute resources evenly when they are earned collaboratively (Warneken, Lohse, Melis, \& Tomasello, 2011). Based on these findings, we asked whether children would be more sensitive to proportion in a "Giving Game" when resources were earned collaboratively by a giver and a recipient, rather than by the giver in isolation.

\section{STUDY 1}

In Study 1, we tested 5-year-olds' sensitivity to proportion when assessing the "niceness" of givers in order to replicate McCrink et al. (2009). We also tested 7-year-olds and adults to explore the later development of these judgments. Finally, we conducted a preliminary investigation of whether children's evaluations of givers differ as a function of how resources are obtained.

\section{Method}

Subjects-Subjects were 8 five-year-olds $(M=5.56, S D=.23$; 6 female), 8 seven-yearolds $(M=7.38, S D=.29 ; 6$ female), and 14 undergraduate students $(M=21.87, S D=1.13$; 10 female). Children were recruited from schools in Northern and Southern California, and the sample was approximately 56\% Asian American and 44\% Caucasian. The adult sample was approximately 71\% Asian American, 21\% as Caucasian, and 7\% African-American.

Procedure-All child participants were tested individually using a method similar to the "Giving Game" of McCrink et al. (2009). A series of scenarios were presented in which three different children were depicted using line drawings: two givers, who shared some pennies, and one recipient, who received the pennies. Actual pennies and plates were used, with a plate assigned to each giver and recipient to hold pennies. The act of giving was depicted by moving pennies from a giver's plate to a recipient's plate. The same procedure was used for adults, but without the use of any props. Instead, the number of pennies given to each character was described verbally.

For both groups of subjects, the number of pennies each giver had initially and the number that he or she gave to the recipient were manipulated systematically across trials.

Niceness Comparisons: The niceness comparisons included eight conflict trials and two control trials that were presented in one of four random orders. On each trial, subjects were asked to judge which of two givers was nicer.

On conflict trials, the proportion of pennies given was pitted against absolute amount given to the recipient: one giver gave a greater absolute number but a smaller proportion of their pennies, and the other giver gave a greater proportion but a smaller absolute number. Four comparisons were used across the eight conflict trials, each repeated twice: 4/20 vs. 2/4; 
$2 / 10$ vs. $1 / 2 ; 8 / 40$ vs. $4 / 8$; and $4 / 40$ vs. $2 / 2$. For example, on two different test trials one giver gave 4 of her 20 pennies and the other gave 2 of her 4 pennies.

On the two control trials, one giver shared 2 of 20 pennies and the other shared 4 of 4 pennies. These trials were used to verify that the subjects were attending to the number of pennies given.

Niceness Ratings: After completing the comparison task the same group of subjects also performed a ratings task in which they heard narratives like those in the first task. Subjects were randomly assigned to either the collaborative effort condition or the individual effort condition. In the collaborative effort condition subjects were told, "These children [the giver and the recipient] worked a long time together to earn these 20 coins." In the individual effort condition subjects were told, "This child [giver] worked a long time by himself/herself to earn these 20 coins." After the participant was told how the giver obtained the pennies, they were shown the distribution of resources. In both effort conditions, they saw a giver give 4 of 20 pennies to a recipient. Subjects were then asked to rate the niceness of givers on a 5-point scale from 1 (very mean) to 5 (very nice). Children were first asked to judge whether the giver was "nice," "in the middle," or "mean." Those who responded with "nice" were asked, "How nice?" and were provided with the possible responses "very nice" or "a little nice." Subjects who responded with "mean" were asked, "How mean?" and were provided with the possible responses "very mean" or "a little mean." Adults were simply asked to respond to the complete scale.

\section{Results and Discussion}

Niceness comparisons-Adults favored proportion over absolute quantity when judging which giver was nicer, whereas 5- and 7-year-olds were more likely to base their comparisons of givers on the absolute amount shared (see Figure 1; see the Appendix for response patterns on conflict niceness comparison trials broken down by individual subjects). This was confirmed by a repeated measures analysis of variance (ANOVA), with age (5-year-old, 7-year-old, Adult) as a between-subjects factor, trial type (Conflict, Control) as a within-subjects factor, and percentage of proportional responses (selecting the nicer giver based on proportion shared) as the dependent variable. There was a significant effect of trial type, $F(1,27)=100.52, p<.001$, with conflict trials eliciting lower levels of proportional responses than control trials ( $M=41.1 \%$ vs. $92.6 \%$, respectively). There was also a significant effect of age, $F(2,27)=31.88, p<.001$, with older subjects giving higher levels of proportional responses (5-year-olds: 43.8\%; 7-year-olds: 61.7\%; adults: $95.1 \%$ ). Follow-up Tukey's tests showed the differences between the adults and the two younger groups were each significant at the $p<.001$ level and the difference between the two younger groups was marginally significant, $p=.063$. Finally, there was an interaction between age and trial type, $F(2,27)=27.10, p<.001$. To explore this interaction, one-way ANOVAs were conducted on control and conflict trials with age as the between-subjects variable and proportional response as the dependent variable. As illustrated in Figure 1, significant differences were found across ages for the conflict trials, $F(2,29)=62.05, p<$. 001 , but not for control trials, $F(2,29)=1.86, p=.175$, for which all age groups judged that the individual who gave the larger amount was nicer (5-year-olds: 81.3\%; 7-year-olds: 100\%; adults: 96.4\%). Tukey's post hoc analyses indicated that on conflict trials adults were more likely to label proportional givers as nicer ( $93.8 \%$ of the time) relative to both 5-yearolds $(6.3 \%), p<.001$, and 7 -year-olds $(23.4 \%), p<.001$, but that there was not a significant difference between 5- and 7-year-olds, $p=.20$.

Overall, children favored givers when they gave greater absolute amounts, whereas adults favored givers who gave proportionally more. This result replicates the findings of McCrink 
et al. (2009) and suggests that children's tendency to favor absolute amount over proportion persists until after the age of 5 .

Niceness ratings-In this task, subjects in all age groups gave significantly higher niceness ratings to givers who earned pennies individually, $M=3.83$, rather than in collaboration with recipients, $M=2.48$. This result was confirmed by a $3 \times 2$ ANOVA with age (5-year-old, 7-year-old, Adult) and effort type (Individual, Collaborative) as betweensubjects factors, and niceness rating (from 1-7) as the dependent variable. There was a significant effect of effort type, $F(1,24)=12.38, p<.005$. There were no other main effects or interactions. Thus, children and adults were sensitive to how resources were acquired.

In sum, although children were unlikely to focus on proportion information in noncollaborative contexts, their niceness ratings were strongly affected by how they thought resources were acquired, and whether the recipient was entitled to receive an equal share. This finding suggests that children should be sensitive to proportion when tested in collaborative contexts. We examined this possibility in Study 2 .

\section{STUDY 2}

In Study 1, both 5- and 7-year-olds were more sensitive to absolute quantity shared than to proportion when judging the niceness of givers. We also found preliminary evidence that niceness judgments were influenced by how the resources were acquired. When resources were earned individually, children judged the givers to be nicer than when they were acquired collaboratively (where an expectation of equitable resource distribution may have arisen). These results suggest an explanation for why children are insensitive to proportion in contexts like the one reported by McCrink et al. (2009). In individual-effort contexts, children may believe that leftover resources are irrelevant to assessing an individual's act of giving, since no prior expectation exists about how they should be distributed. In contrast, in collaborative contexts children may attend to all resources because they are concerned with whether they are distributed in an equitable fashion.

In Study 1, we did not manipulate the proportion given in our preliminary exploration of collaborative and individual-effort contexts. Therefore, the study did not provide a direct test of whether collaborative contexts are more likely to generate sensitivity to proportion. We therefore explored this question in Study 2, by manipulating both proportion and effort type in a single experiment.

\section{Method}

Subjects-Subjects were 183 - to 5-year-olds ( $M=4.48, S D=.87$; 8 female), 36 6- to 8year-olds $(M=7.27, S D=.92 ; 11$ female $)$, and 20 undergraduate students $(M=21.31, S D=$ $1.14 ; 9$ female). The children were recruited from schools in Southern California, and the sample was approximately 9\% Asian-American, 56\% Caucasian, 4\% Hispanic, 2\% Mexican, and 2\% multiracial. The undergraduate student sample was approximately 50\% Asian-American, 45\% Caucasian, and 5\% Hispanic.

Procedure-All subjects were presented with pairs of trials similar to those used in the niceness comparisons of Study 1. In Study 2, each trial pair included a giver who gave 20\% and another who gave $50 \%$, where the absolute number given in the $20 \%$ case was always greater (i.e., $2 / 10$ versus $1 / 2 ; 8 / 40$ versus $4 / 8 ; 4 / 20$ versus $2 / 4$ ). Subjects were assigned to the collaborative or individual effort condition and heard the corresponding scenarios from Study 1. After each trial, subjects made niceness ratings of each giver, as in Study 1 (except that here they responded on a 7-point scale instead of a 5-point scale). However, subjects aged 6 and older also made niceness comparisons after doing these individual ratings (i.e., 
Which boy do you think is nicer?).1 As a result, the method differed in two ways. First, we did not ask the younger children to make niceness comparisons. Second, instead of doing niceness comparisons, we instead tested the younger children with both effort types (individual and collaborative) as a within-subjects manipulation. These children were first given a block of niceness ratings with the assigned effort type followed by a second set of trials from the opposing context, whereas, children aged 6- to 8-years-old were asked to provide niceness ratings and comparisons for only one effort-condition. Stimuli were identical to those used in Study 1, and, as in that task, they were only used for children.

\section{Results and Discussion}

Niceness ratings-Subjects in all age groups showed sensitivity to proportion and effort in their niceness ratings (see Figure 2). This was confirmed with a $2 \times 2 \times 3$ repeated measures ANOVA with proportion $(20 \%, 50 \%)$ as a within subjects factor, effort (Individual, Collaborative), and age (3- to 5-year-old, 6- to 8-year old, Adult) as between-subjects factors, and niceness rating as the dependent variable. Overall, givers who shared $50 \%$ of their pennies were rated as nicer, $M=5.55$, than those who shared only $20 \%, M=4.23, F(1$, $68)=76.96, p<.001$. Also, givers who earned pennies individually were rated as nicer, $M=$ 5.45 than those who earned their pennies collaboratively, $M=4.33, F(1,68)=16.32, p<$. 001 . There was a significant interaction between proportion and age, $F(2,68)=12.85, p<$. 001, but no interaction between age and effort type; all age groups provided higher niceness ratings to givers who earned their pennies individually (see Figure 2).

Finally, there was a significant interaction between proportion and effort type, $F(1,68)=$ $34.56, p<.001$, which reflected the fact that subjects were more sensitive to proportion on collaborative trials than on individual effort trials. Givers who shared $50 \%$ were judged nicer than those giving $20 \%$ across both individual contexts, $t(36)=2.24 p<.05$, and collaborative contexts, $t(36)=8.51, p<.001$. Within each age group there was a significant effect of proportion for collaborative trials (all $p<.05$ ) whereas only adults showed an effect of proportion for individual effort trials.

There was no significant interaction between proportion, effort type, and age, suggesting that the different sensitivity to proportion across the individual and collaborative effort trials did not change significantly over development.

Niceness comparisons-A $2 \times 2$ ANOVA was conducted with age (6- to 8-year-olds, Adults), and effort type (Collaborative, Individual) as between-subjects factors and the mean percentage of proportional responses (judging the giver who shared a larger proportion to be nicer) as the dependent variable. There was a significant main effect of effort type, $F(1,52)$ $=11.14, p<.01$, with higher levels of proportional responses on collaborative effort trials, $M=94.4 \%$, than on individual effort trials, $M=67.6 \%$. There was also a significant main effect of age, $F(1,52)=22.27, p<.001$. Planned comparisons found that adults selected the giver who shared a larger proportion, $M=100 \%$, to a greater degree than 6- to 8-year-olds, $M=62 \%$.

A significant interaction between age and effort type was also found, $F(1,52)=11.14, p<$. 01. As shown in Figure 3, 6- to 8-year-olds used proportion as the basis for deciding who was nicer significantly more in the collaborative effort condition, $M=88.9 \%$, than in the individual effort condition, $M=35.2 \%, t(34)=4.52, p<.001$. In contrast, adults always based their judgments on proportion regardless of condition (see the Appendix for response

\footnotetext{
${ }^{1}$ The younger 3- to 5-year-old children were tested only after data collection for the older group was complete, and were originally tested with the intent of presenting them in a separate experiment. Therefore, small differences in design exist for the different age groups, as noted in the text.
} 
patterns broken down by individual subjects). Interestingly, compared to the younger children tested in Study 1, 6- to 8-year-old children in this experiment were somewhat more likely to favor proportional givers in the individual effort condition (though they still showed a preference for absolute amount relative to children tested in the collaborative condition). This is consistent with a gradual developmental change in how children assess acts of giving.

The results of this experiment, combined with those of Study 1, suggest that both adults and children as young as 3 years old are sensitive to proportion when evaluating the niceness of givers. However, we also found that children are more likely to consider proportion when resources are earned in a collaborative context than when they are earned by the giver alone. When resources were earned individually, children were less sensitive to proportion. Adults, in contrast, were sensitive to proportion regardless of how resources were acquired.

These results are consistent with the idea that children are more sensitive to proportion information in situations that invoke intuitions of merit - i.e., when they have expectations about how resources should be distributed. When children evaluate givers they appear to take this expectation into account and expect them to allocate 50\% to their collaborator. Despite this apparent sensitivity to proportion, children nonetheless focused more on absolute amount when there were no expectations about how resources should be distributed. In non-collaborative contexts, children did not consider leftover resources when making their judgments, resulting in a failure to consider proportions. This is in contrast to adults, who appeared to evaluate the niceness of givers relative to their total available resources, resulting in effects due to proportion.

In the General Discussion, we explore the nature of this developmental difference. First, however, we sought to replicate these findings when identical methods are used for children and adults, and when controlling for socio-economic and ethnic differences between groups. To do this, Study 3 directly compared children to their caregivers using a single procedure for all subjects.

\section{STUDY 3}

In Study 3 we compared children's judgments directly to those of their caregivers, and used identical methods for all subjects. Also, we added measures to verify that subjects remembered and understood what was being asked of them.

\section{Method}

Subjects-A total of 22 5- and 6-year-old children $(M=5.91, S D=.56 ; 9$ female $)$ and 22 parents or guardians ( 20 female) participated. The sample was approximately $77 \%$ Caucasian, 5\% Latin American, and 18\% multi-racial.

Procedure-The procedure was based on that of Study 2. All subjects were asked about both collaborative and individual effort situations (within-subjects), and were asked to make both niceness ratings and niceness comparisons. Adults and children were run using identical methods, with the stimuli and 7-point rating scales from Study 2.

Study 3 also included a set of manipulation checks to verify that subjects remembered and understood critical aspects of the experiment. After the last trial in the collaborative effort condition and the last trial in the individual effort condition, subjects were asked to recall whether the giver on that trial had worked alone or collaboratively. Also, in order to evaluate subjects' ability to assess differences in absolute magnitude, they were asked indicate who gave more: a giver who gave 2 out of 10 versus one who gave 5 out of 10 . 


\section{Results and Discussion}

Niceness ratings-A $2 \times 2 \times 2 \times 2$ ANOVA was conducted with block order (Collaborative, Individual) and age (Children, Adults) as between-subjects variables, and with proportion $(20 \%, 50 \%)$ and effort type (Individual, Collaborative) as within-subjects variables. The dependent variable was niceness rating. We found significant main effects of effort type, $F$ $(1,40)=233.58, p<.001$, and proportion, $F(1,40)=67.02, p<.001$. Givers received higher niceness ratings when they earned resources individually, $M=5.99$, than when they earned them collaboratively with the recipient, $M=4.53$, and this was true of both adults and children when analyzed separately ( $p<.05$ for each). Also, givers who shared $50 \%$ of their pennies were given greater niceness ratings, $M=6.17$, than those who shared only $20 \%, M=4.35$, which was also true for children and adults taken separately $(p<.01$ for each). There were also significant 2-way interactions of proportion and effort type, $F(1,40)$ $=78.73, p<.001$, effort type and age, $F(1,40)=156.00, p<.001$, and proportion and age, $F(1,40)=6.96, p<.05$, as well as a 3-way interaction between age, effort type, and proportion, $F(1,40)=66.42, p<.001$. Each of these interactions can be explained as stemming from adults' relatively sharp differentiation of givers who gave $20 \%$ vs. $50 \%$ in collaborative contexts. More specifically, adults gave relatively low ratings to givers who gave only $20 \%$ in the collaborative contexts. For example, for the collaborative effort contexts, children and adults gave similar ratings to givers who gave 50\% $(M=5.82$ and 5.91 respectively), whereas children gave significantly higher ratings than adults to givers who gave only $20 \%$ ( $M=4.52$ and 1.89 respectively). Still, despite this difference, children were nonetheless sensitive to effort-type; they gave higher niceness ratings to givers who shared $20 \%$ of their resources if they earned them individually, $M=4.85$, than if they earned them collaboratively, $M=4.52, t(21)=2.54, p<.05$, while no difference was found between individual effort, $M=6.02$, and collaborative effort, $M=5.82$, for givers who shared $50 \%$ of their resources, $t(21)=1.05, p=.307$.

Like Studies 1 and 2, these findings suggest that both children and adults are sensitive to proportion and to the context in which resources are obtained when judging givers, although these results suggest that adults may be more sensitive to context than children when making niceness ratings.

Niceness comparisons-Next we examined niceness comparisons. The mean percentage of proportional responses (selecting the giver who shared a larger proportion as nicer) was analyzed in a $2 \times 2 \times 2$ ANOVA with block order (Individual, Collaborative) and age (5- and 6-year-olds, Adults) as between-subjects variables and effort type (Individual, Collaborative) as a within-subjects variable. Significant main effects of effort type and age were found; subjects were more likely to consider proportion in their niceness comparisons when the givers earned their resources collaboratively, $M=79.5 \%$, rather than individually, $M=70.5 \%, F(1,40)=5.81, p<.05$. Also, adult subjects, $M=95.5 \%$, provided more proportional responses than children, $M=54.5 \%, F(1,40)=24.38, p<.001$, consistent with a developmental change from an emphasis on absolute number to an emphasis on proportion. Notably, adults focused on proportion regardless of condition. However, it is possible that adults did in fact differentiate between the conditions, but the difference went undetected due to ceiling effects.

To confirm that only adults were sensitive to proportion in non-collaborative contexts (as suggested by the results of Study 2), paired t-tests were conducted for children and for adults. As shown in Figure 5, whereas children were more sensitive to proportion when comparing givers who earned their resources collaboratively than when comparing givers who earned resources individually, $M c=62.1 \%, M i=47 \%, t(21)=2.34, p<.05$, this difference was not observed in adults, $M c=97 \%, M i=93.9 \%, t(21)=.81, p=.427$. Adults 
showed greater sensitivity to proportion than children across both individual, $t(42)=4.64, p$ $<.001$, and collaborative effort conditions, $t(42)=3.83, p<.001$ (see the Appendix for response patterns broken down by individual subjects). These results suggest that children can use proportion information as a basis of their niceness judgments but that this sensitivity to proportion is stronger in situations where resources are earned collaboratively and an expectation of equal resource distribution is present.

Manipulation check-When asked to recall how givers earned resources on each trial adults responded with 100\% accuracy. Among children, 77\% responded with 100\% accuracy, $18 \%$ missed one of the two questions and 5\% missed both. Subjects also performed well when asked to assess differences in absolute magnitude: $100 \%$ of adults and $95 \%$ of children correctly indicated that an individual who gave 5 out of 10 gave more than an individual who gave 2 out of 10 .

\section{GENERAL DISCUSSION}

In three experiments we found that young children are often sensitive to proportion when evaluating acts of sharing. However, we also found that children's sensitivity to proportion is selective: they were more likely to favor a proportional distribution of resources when givers earned the resources in collaboration with recipients, rather than independently. Consistent with previous reports (McCrink et al., 2009), we found that children often focused on absolute amount rather than proportion when evaluating givers who shared individually earned resources, unlike adults who always considered proportion. Our results also suggest that those previous findings extend to cases where children are reasoning about others rather than about their own personal gain, suggesting that children's neglect of proportional information in these contexts is not a function of selfishness.

These data indicate three important findings. First, they suggest that children between 3 and 5 years of age are sensitive to relative amount when reasoning about resource distribution. By testing children in collaborative contexts, we showed a robust sensitivity to proportion at younger ages than reported in previous studies. This finding contributes to a growing body of evidence suggesting that, from early in development, children are able to process quantities proportionally when proportion information is salient (Barth, Baron, Spelke, \& Carey, 2009; Goswami, 1995; McCrink \& Wynn, 2007; Mix, Levine, \& Huttenlocher, 1999; Singer-Freeman \& Goswami, 2001; Spinillo \& Bryant, 1991).

Second, the results suggest that both adults and young children expect collaboratively earned resources to be divided evenly when individuals have contributed equally to acquiring them. This finding is consistent with a wide body of data from psychology and behavioral economics demonstrating that adults are sensitive to the origin of resources when evaluating their distribution (Cappelen et al., 2007; Cherry, Frykblom, \& Shogren, 2002; Frohlich et al., 2004; Oxoby \& Spraggon, 2008; Ruffle, 1998). Also, they are consistent with previous reports of context-sensitivity in children's moral reasoning and behavior ( $\mathrm{Fu}, \mathrm{Xu}, \mathrm{Cameron}$, Heyman, Lee, 2007; Heyman, Sweet, \& Lee, 2008; McGillicuddy-De Lisi, De Lisi, \& Van Gulik, 2008; McGillicuddy-De Lisi, Watkins, \& Vinchur, 1994; Smetana, 2006). For example, McGillicuddy-De Lisi et al. (1994) found that sixth graders were more likely to share resources with a person in need if they were a friend rather than a stranger. Also, McGillicuddy-De Lisi et al. (2008) found that twelfth graders were more likely to focus on equity in a work context than in an educational context. In our study, children also attended to the context in which resources were earned, and did not base their evaluations of givers strictly on the amount they gave. 
Third, we found an important developmental difference between children and adults. Whereas adults evaluated givers in a relative fashion when they gave generously (i.e., in individual effort contexts), children did not and showed no preference for givers who gave a greater proportion. This is despite the fact that children were clearly sensitive to proportion. This raises the question: if children are sensitive to proportion and able to use it to guide reasoning about equitable resource distribution, then why do they, unlike adults, fail to use proportion when evaluating non-collaborative contexts?

To understand this issue, it is important to consider the precise nature of this developmental difference. In Studies 2 and 3, both children and adults were very positive in their evaluation of non-collaborative givers, and generally produced ratings of "nice" or "very nice". In fact, only when givers in collaborative contexts failed to give proportionally did subjects in either group deviate from this pattern. In this respect, children's general pattern of responses was very much adult-like. The key difference between children and adults was in how they compared givers across different conditions. Once they had made their niceness ratings, children tested in the individual effort context favored givers who gave a greater absolute amount. In contrast, in collaborative effort contexts children favored givers who gave a greater proportion of available resources? Thus, the difference between children and adults cannot be explained as a failure by children to compute proportions or to contrast proportion with absolute amount. Instead, the data suggest that children were simply indifferent to proportion when assessing givers in non-collaborative contexts. For the youngest children these situations were not evaluated according to what recipients could have received, but instead according to what they did receive.

Why might comparisons differ between children and adults? We see two broad possibilities. First, it is possible that children, unlike adults, do not weight the value of resources relative to their availability, and thus may not recognize that giving $\$ 10$ has an greater impact on a giver who begins with $\$ 20$ relative to one who begins with $\$ 100$. Unlike children, adults may believe that the impact of sharing on a giver is proportional to their ability to give. This belief may emerge slowly over development, accounting for the pattern findings reported here.

A second possibility is that, for young children, giving any amount in individual effort contexts is fair (and thus "nice") because they have a stronger default tendency to view people as having positive psychological characteristics (Boseovski \& Lee, 2008) and because they may believe that we only deserve to receive what we earn, and are not entitled to the resources of other people no matter how rich they are. Unshared resources may therefore be irrelevant to assessing generosity in individual effort contexts, resulting in an apparent insensitivity to proportion in their judgments. In contrast, adult intuitions of generosity do take account of unshared resources, suggesting that for them these resources are relevant even when notions of merit do not come into play. On this hypothesis, the difference between children's and adults' reasoning about generosity may involve a gradual extension of intuitions of fairness from contexts that involve merit (like the collaborative contexts presented here) to contexts that do not. For example, children may view resource distribution in terms of effort and merit, whereas adults may view it in terms of more abstract moral intuitions related to sharing and altruism.

The present research does not offer clear support for either account. However, if either is correct we might predict cross-cultural differences (see Keats \& Fang, 1996; Rochat et al., 2009). For example, it is possible that differences exist between children in the US and children raised in cultures that place a greater emphasis on collectivist values, with less focus on individual effort (Rochat et al., 2009). Also, these alternatives may be differentiated by studies that vary the motives of givers, (Heyman \& Gelman, 1998), 
whether they give anonymously (Cherry et al., 2002), and what is normative in a particular setting (Kalish \& Lawson, 2008; Kalish \& Shiverick, 2004).

Future research should also explore situations in which collaborators contribute differently towards earning resources, and whether children are sensitive to differences in productivity when tested with similar methods (see Almås, Cappelen, Sørensen, \& Tungodden, 2010). Children may also have different expectations when recipients belong to different social groups (Fehr, Bernhard \& Rockenbach, 2008), and based on whether givers are individuals or groups (Kugler, Bornstein, Kocher, \& Sutter, 2007). Further, future work should examine how children reason about different proportions. In the present research we focused on the contrast between giving $20 \%$ versus $50 \%$. This leaves open the possibility that relative amounts like 50\% represent a special case. Although our study makes clear that children are able to reason about relative amounts, it is possible that 50-50 sharing is particularly salient to children in early development. As a result, children may reason differently when different proportions are fairly shared, or when more than two individuals collaborate to acquire resources.

Such studies will help to contribute to understanding differences between children and adults, and how children's understanding of generous giving changes over development.

To conclude, the present study investigated the origin of adult intuitions about resource distribution and generosity. We examined: Do humans spontaneously evaluate acts of giving according to what a person is able to give, or do we learn to value proportional giving as a function of culturally-mediated learning experience? Our studies show that children's previously reported focus on absolute amount when evaluating generosity cannot be explained by a generalized insensitivity to proportion. Instead, children are sensitive to relative amount (e.g., in collaborative contexts), but they do not view such information as relevant when resources are earned by a lone individual (non-collaboratively). This finding suggests that unlike adults, children do not expect individuals to share resources according to their ability to do so, and that they judge generosity in terms of the actual benefits acquired, rather than on the basis of the giver's potential to give.

\section{Acknowledgments}

This research was supported by a grant from NICHD (R01 HD048962). We would like to thank Brian Compton, Yarrow Dunham, Edmund Fantino, Kimberly Vanderbilt, Katie Wagner, and Piotr Winkielman for helpful comments on the manuscript.

\section{REFERENCES}

Almås I, Cappelen AW, Sørensen EO, Tungodden B. Fairness and the development of inequality acceptance. Science. 2010; 328:1176-1178. [PubMed: 20508132]

Barth H, Baron A, Spelke E, Carey S. Children's multiplicative transformations of discrete and continuous quantities. Journal of Experimental Child Psychology. 2009; 103:441-454. [PubMed: 19289237]

Boseovski JJ, Lee K. Seeing the world through rose-colored glasses? Neglect of consensus information in young children's personality judgments. Social Development. 2008; 17:399-416. [PubMed: 20930951]

Kugler T, Bornstein G, Kocher MG, Sutter M. Trust between individuals and groups: Groups are less trusting than individuals but just as trustworthy. Journal of Economic Psychology. 2007; 28:646657.

Cappelen AW, Hole AD, Sorensen EO, Tungodden B. The pluralism of fairness ideals: An experimental approach. The American Economic Review. 2007; 97:818-827. 
Cherry TL, Frykblom P, Shogren JF. Hardnose the dictator. The American Economic Review. 2002; 92:1218-1221.

Damon W. Early conceptions of positive justice as related to the development of logical operations. Child Development. 1975; 46:301-312.

Damon, W. The social world of the child. San Francisco: Jossey-Bass Publishers; 1977.

Fehr E, Bernhard H, Rockenbach B. Egalitarianism in young children. Nature. 2008; 454:1079-1083. [PubMed: 18756249]

Frohlich N, Oppenheimer J, Kurki A. Modeling other-regarding preferences and an experimental test. Public Choice. 2004; 119:91-117.

$\mathrm{Fu} \mathrm{G}, \mathrm{Xu}$ F, Cameron CA, Heyman GD, Lee K. Cross-cultural differences in children's choices, categorizations, and evaluations of truth and lies. Developmental Psychology. 2007; 43:278-293. [PubMed: 17352539]

Goswami U. Transitive relational mappings in three- and four-year-olds: The analogy of Goldilocks and the Three Bears. Child Development. 1995; 66:877-892.

Heyman GD, Gelman SA. Young children use motive information to make trait inferences. Developmental Psychology. 1998; 34:310-321. [PubMed: 9541783]

Heyman GD, Gelman SA. The use of trait labels in making psychological inferences. Child Development. 1999; 70:604-619. [PubMed: 10368912]

Heyman GD, Sweet MA, Lee K. Children's reasoning about lie-telling and truth-telling in polite contexts. Social Development. 2008; 18:728-746. [PubMed: 21072132]

Hook J. The development of equity and logico-mathematical thinking. Child Development. 1978; 49:1035-1044.

Hook J, Cook T. Equity theory and the cognitive ability of children. Psychological Bulletin. 1979; 86:429-445.

Inhelder, B.; Piaget, J. The early growth of logic in the child. New York: Routledge \& Kegan Paul; 1964.

Kalish CW, Lawson CA. Development of social category representations: Early appreciation of roles and deontic relations. Child Development. 2008; 79:577-593. [PubMed: 18489414]

Kalish CW, Shiverick SM. Children's reasoning about norms and traits as motives for behavior. Cognitive Development. 2004; 19:401-416.

Keats, DM.; Fang, FX. The development of concepts of fairness in rewards in Chinese and Australian children. In: Grad, H.; Blanco, A.; Georgas, J., editors. Key issues in cross-cultural psychology. Amsterdam: Swets \& Zeitlinger; 1996. p. 276-287.

Lane I, Coon R. Reward allocation in preschool children. Child Development. 1972; 43:1382-1389.

McCrink K, Bloom P, Santos LR. Children's and adults' judgments of equitable resource distributions. Developmental Science. 2009; 13:37-45. [PubMed: 20121861]

McCrink K, Wynn K. Ratio abstraction by 6-month-old infants. Psychological Science. 2007; 18:740745. [PubMed: 17680947]

McGillicuddy-De Lisi AV, De Lisi R, Van Gulik K. The effects of grade level, context, and family type on male and female adolescents' distributive justice reasoning. Journal of Adolescence. 2008; 31:107-124. [PubMed: 17583786]

McGillicuddy-De Lisi AV, Watkins C, Vinchur AJ. The effect of relationship on children's distributive justice reasoning. Child Development. 1994; 65:1694-1700. [PubMed: 7859550]

Mix KS, Levine SC, Huttenlocher J. Early fraction calculation ability. Developmental Psychology. 1999; 35:164-174. [PubMed: 9923472]

Noelting G. The development of proportional reasoning and the ratio concept: Part 1 The differentiation of stages. Educational Studies in Mathematics. 1980; 11:217-253.

Oxoby RJ, Spraggon J. Mine and yours: Property rights in dictator games. Journal of Economic Behavior and Organization. 2008; 65:703-713.

Piaget, J.; Inhelder, B. The growth of logical thinking. New York: Basic Books; 1958.

Piaget, J.; Inhelder, B. The origin of the idea of chance in children. New York: Norton; 1975.

Reyna VF, Brainerd CJ. Numeracy, ratio bias, and denominator neglect in judgments of risk and probability. Learning and Individual Differences. 2008; 18:89-107. 
Reyna, VF.; Brainerd, CJ. The origins of probability judgment: A review of data and theories. In: Wright, G.; Ayton, P., editors. Subjective Probability. New York: Wiley; 1994. p. 239-272.

Rochat P, Dias MDG, Liping G, Broesch T, Passos-Ferreira C, Winning A, Berg B. Fairness in distributive justice in 3- and 5-year-olds across seven cultures. Journal of Cross-Cultural Psychology. 2009; 40:416-442.

Ruffle BJ. More is better, but fair is fair: Tipping in dictator and ultimatum games. Games and Economic Behavior. 1998; 23:247-265.

Siegler RS, Vago S. The development of a proportionality concept: Judging relative fullness. Journal of Experimental Child Psychology. 1978; 25:371-395.

Singer-Freeman KE, Goswami U. Does half a pizza equal half a box of chocolates? Proportional matching in an analogical task. Cognitive Development. 2001; 16:811-829.

Smetana, JG. Social-cognitive domain theory: Consistencies and variations in children's moral and social judgments. In: Killen, M.; Smetana, JG., editors. Handbook of moral development. Mahwah, NJ: Erlbaum; 2006. p. 119-153.

Spinillo AG, Bryant P. Children's proportional judgments: The importance of "half.". Child Development. 1991; 62:427-440.

Warneken F, Lohse K, Melis A, Tomasello M. Young children share the spoils after collaboration. Psychological Science. 2011; 22:267-273. [PubMed: 21196533]

\section{APPENDIX}


Percent of Subjects in Study 1 Who Chose Proportional Reasoning, by Frequency

\begin{tabular}{lrr}
\hline Frequency & Children & Adults \\
\hline never & 56.3 & 0.0 \\
1 trial & 6.3 & 0.0 \\
2 trials & 25.0 & 0.0 \\
3 trials & 6.3 & 0.0 \\
4 trials & 0.0 & 7.1 \\
5 trials & 0.0 & 7.1 \\
6 trials & 0.0 & 0.0 \\
7 trials & 6.3 & 0.0 \\
8 trials & 0.0 & 85.7 \\
\hline
\end{tabular}

Dev Psychol. Author manuscript; available in PMC 2012 September 1. 
Percent of Subjects in Study 2 Who Chose Proportional Reasoning, by Frequency

\begin{tabular}{lcrrrr}
\hline & \multicolumn{2}{c}{ Individual Condition } & & \multicolumn{2}{c}{ Collaborative Condition } \\
\cline { 2 - 3 } \cline { 6 - 6 } Frequency & Children & Adults & & Children & Adults \\
\hline never & 44.4 & 0.0 & & 11.1 & 0.0 \\
1 trial & 22.2 & 0.0 & 0.0 & 0.0 \\
2 trials & 16.7 & 0.0 & & 0.0 & 0.0 \\
3 trials & 16.7 & 100.0 & & 88.9 & 100.0 \\
\hline
\end{tabular}


Percent of Subjects in Study 3 Who Chose Proportional Reasoning, by Frequency

\begin{tabular}{lrrrcr}
\hline & \multicolumn{2}{c}{ Individual Condition } & & \multicolumn{2}{c}{ Collaborative Condition } \\
\cline { 2 - 3 } \cline { 6 - 6 } Frequency & Children & Adults & & Children & Adults \\
\hline never & 31.8 & 0.0 & & 22.7 & 0.0 \\
1 trial & 31.8 & 9.1 & & 13.6 & 0.0 \\
2 trials & 0.0 & 4.5 & & 18.2 & 9.1 \\
3 trials & 36.4 & 86.4 & & 45.5 & 90.9 \\
\hline
\end{tabular}




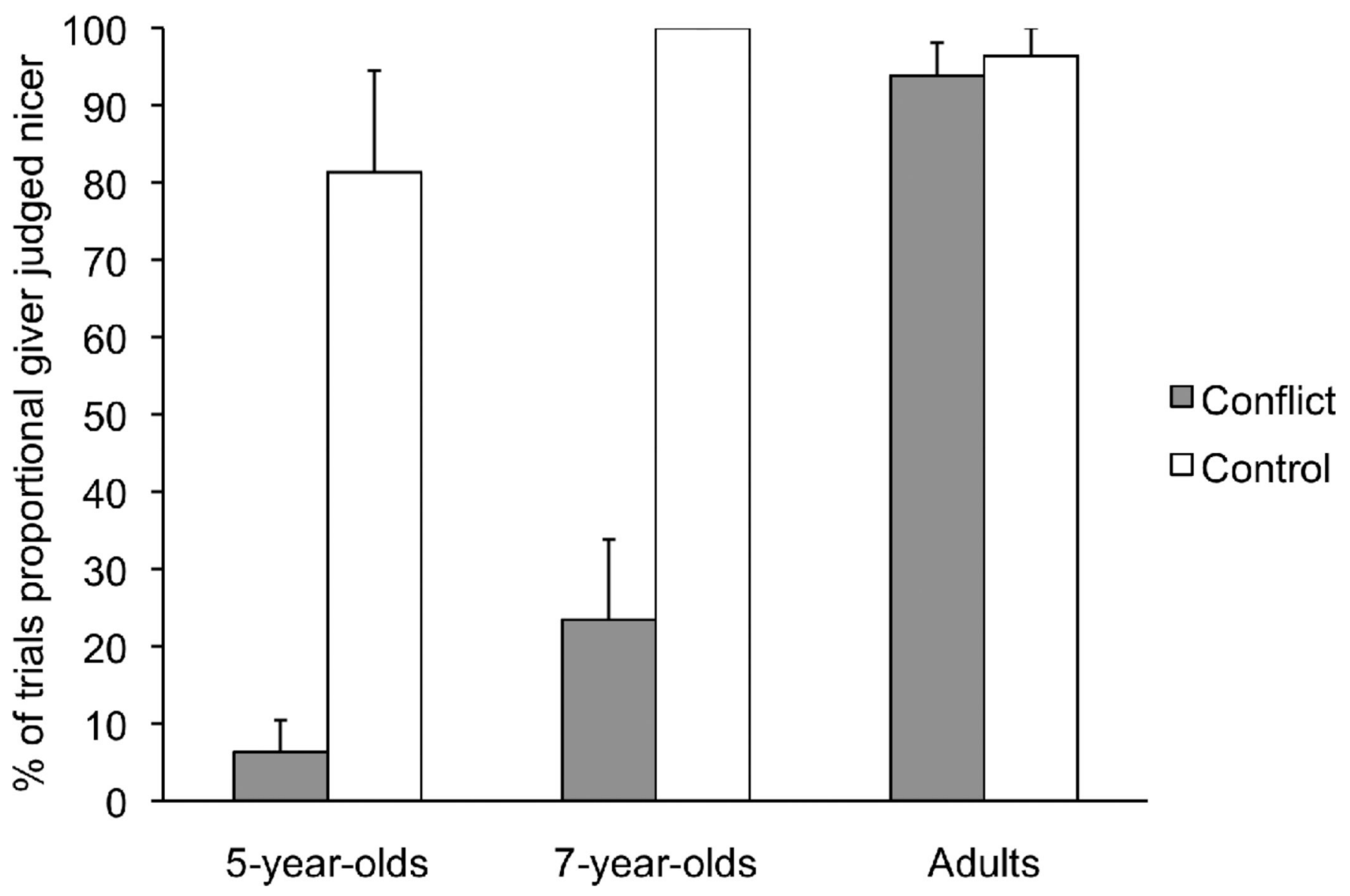

Fig. 1.

Percentage of trials where 5-year-olds, 7-year-olds and adults in Study 1 judged that a giver was nicer when they gave proportionally more on Conflict trials (where the other giver gave a greater absolute amount) and Control trials (where one giver gave a greater proportion and a greater absolute amount). Error bars represent standard error. 


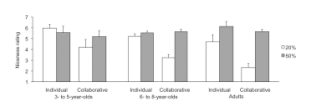

Fig. 2.

Average niceness ratings of givers by adults and children in Study 2 when they gave $20 \%$ or $50 \%$ of their resources obtained through individual or collaborative effort. $1=$ very, very mean and 7 = very, very nice. Error bars represent standard error. 


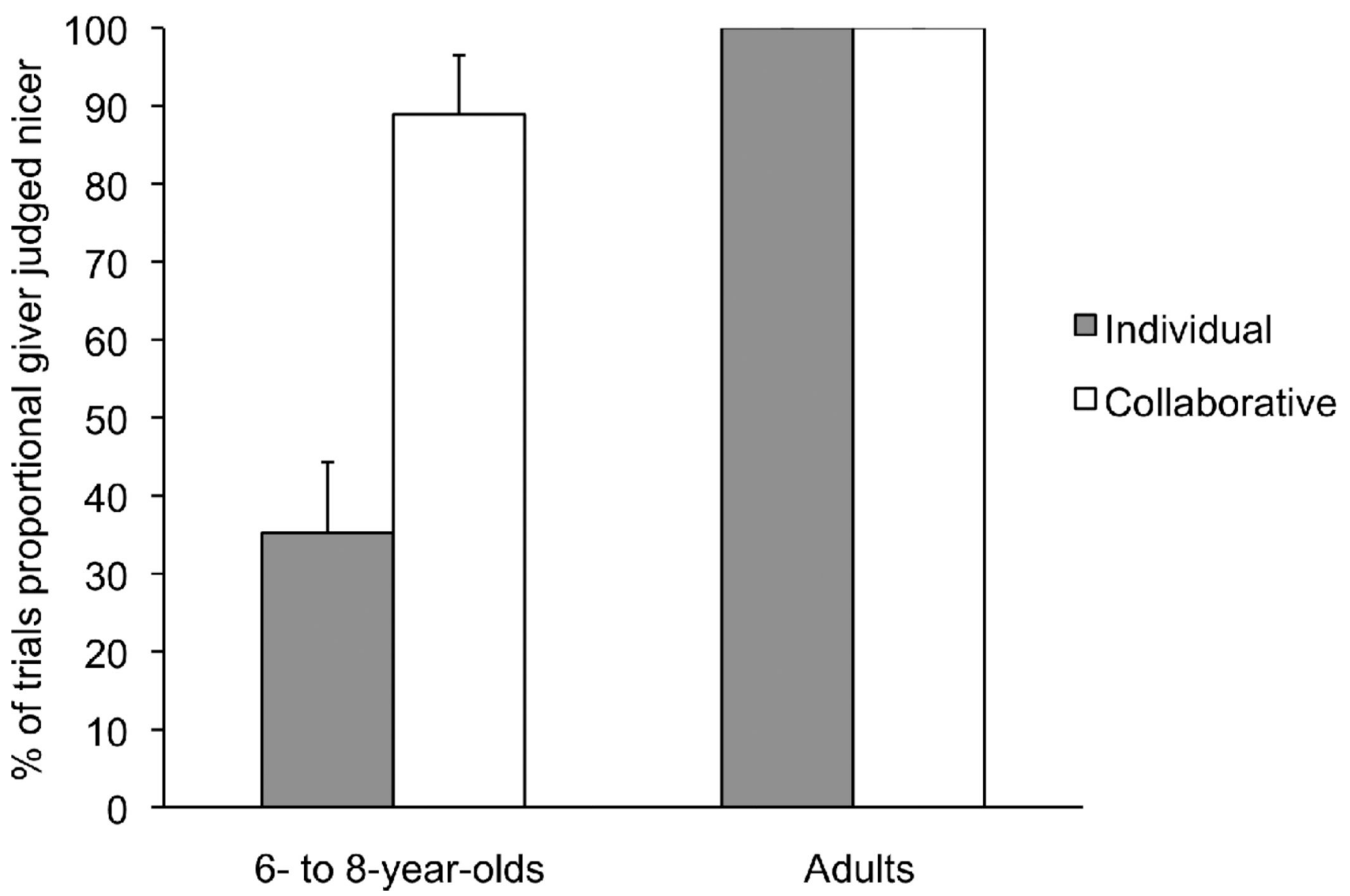

Fig. 3.

Percentage of trials where adults and children in Study 2 judged that a giver was nicer when resources were earned individually or collaboratively. Error bars represent standard error. 


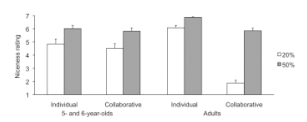

Fig. 4.

Average niceness ratings of givers by adults and children in Study 3 when they gave $20 \%$ or $50 \%$ of their resources obtained through individual or collaborative effort. $1=$ very, very mean and $7=$ very, very nice. Error bars represent standard error. 


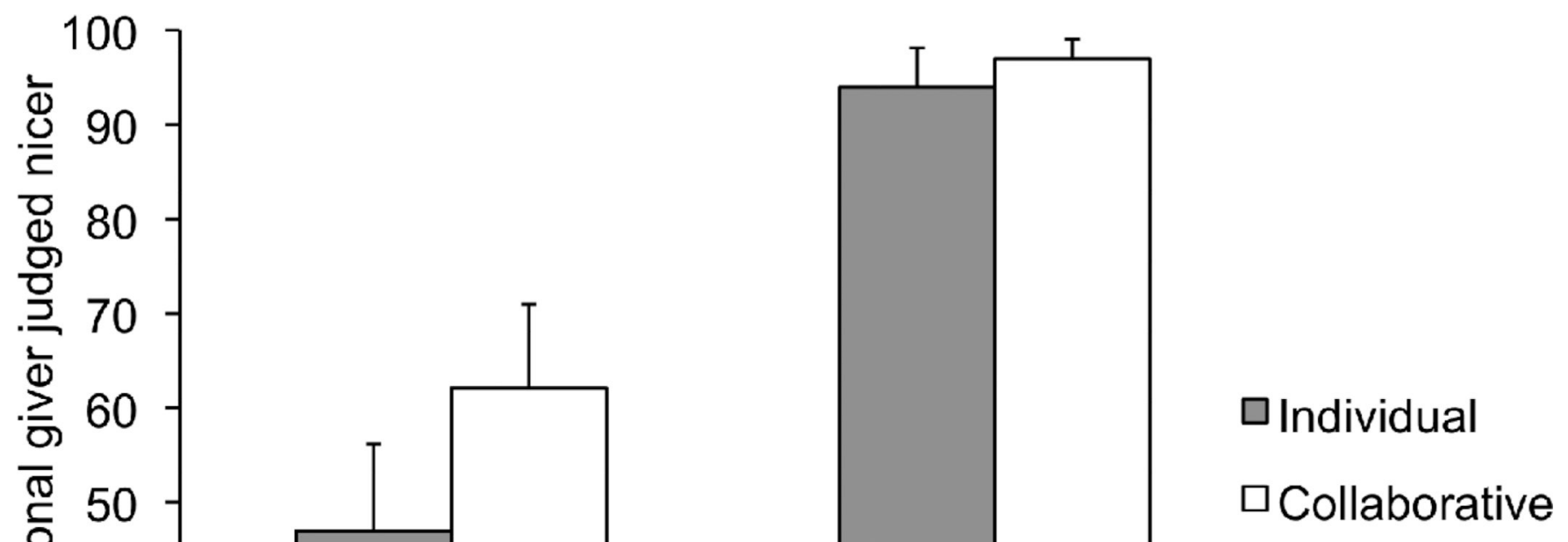

\section{5- and 6-year-olds}

Adults

Fig. 5.

Percentage of trials where adults and children in Study 3 judged that a giver was nicer when resources were earned individually or collaboratively. Error bars represent standard error. 